Article

\title{
Arthrodesis and Hemiarthroplasty: Different Techniques in the Treatment of Hallux Rigidus-Surgery and Postoperative Rehabilitation
}

\author{
Luca Cannavò ${ }^{1}$, Luciano Costarella ${ }^{1}$, Vito Pavone ${ }^{1, *}$, Gianluca Testa ${ }^{1}$, Marco De Gori ${ }^{2}$ and \\ Giuseppe Sessa ${ }^{1}$ \\ 1 Division of Ortopaedic Surgery and Traumatology, University of Catania,Ospedale Vittorio Emanuele, \\ 628 Via Plebiscito, 95154 Catania, Italy; lucacannav@hotmail.it (Luca.C.); lcostarella@yahoo.it (Luci.C.); \\ gianpavel@hotmail.com (G.T.); giusessa@virgilio.it (G.S.) \\ 2 Department of Orthopaedics and Trauma Surgery, Magna graecia University, “Mater Domini” University \\ Hospital, Viale Europa, 88100 Catanzaro, Italy; madegori@hotmail.it \\ * Correspondence: vitopavone@hotmail.com; Tel./Fax: +39-095-743-5398
}

Academic Editor: Giuseppe Musumeci

Received: 15 January 2016; Accepted: 18 February 2016; Published: 25 February 2016

\begin{abstract}
Hallux rigidus (HR) is a progressive degenerative pathology affecting the first metatarsophalangeal joint. The aim of the present study is to report our experience on the treatment of HR patients with two different surgical methods: arthrodesis and hemiarthroplasty. Twelve patients (14 HR) underwent surgery for HR from July 2004 to October 2009. Median age was 58 years (Interquartile Range (IQR) 52.75-65.0). At time of surgery, patients had different grades of HR, according to the Regnauld modified classification. The outcome was assessed using the American Orthopedic Foot and Ankle Society (AOFAS) Hallux Metatarsophalangeal-Interphalangeal (HMI) scale. Controls were performed at one month and then at mid-term follow-up (median 48 months; IQR 29.3-58.0). In the arthrodesis group $(n=6 \mathrm{HR})$ we observed a median improvement of 35.5 points (IQR 34.75-36.0; $p=0.036$ ) at the early follow-up. In the hemiarthroplasty $(n=8 \mathrm{HR})$ group the median of differences at the one-month follow-up was 33 (IQR 30.5-33.0; $p=0.022$ ). At mid-term follow-up the arthrodesis group showed the median difference score of 35 (IQR 33.0-35.25) in comparison with the hemiarthroplasty group which showed a median score of 30.5 (IQR 28.0-32.5). Our results are consistent with the current understanding of two surgical techniques for the treatment of HR: nowadays, arthrodesis is considered the treatment of choice in grade III and IV. Hemiarthroplasty seems to be a promising option. Management of pain and joint flexibility are fundamental to prevent relapses and restore the Range Of Motion (ROM) in dorsal flexion. This article is a retrospective case series with a level of evidence 4 .
\end{abstract}

Keywords: arthrodesis; hallux rigidus; hemiarthroplasty; first metatarsophalangeal joint

\section{Introduction}

Hallux rigidus (HR) is a progressive, degenerative pathology affecting the first metatarsophalangeal (MTP) joint, which was first reported by Davies-Colley [1] in 1887. HR is, after hallux valgus, the most frequent affliction of the first MTP joint, with a prevalence of $2 \%$ in people between 30 and 60 years old in the USA [2]. The etiology is not well established, but appears to be complex, with arthritis, inappropriate use of the shoes, and traumatic events as the most common predisposing factors $[3,4]$. Further predisposing factors are a long first metatarsal bone, flat metatarsal head, pesplanus, dorsiflexion of the first metatarsal, and long and narrow foot. The diagnosis is based on 
clinical and radiographic investigations which show narrowing of the joint space, the presence of dorsal osteophytes, and flattening of the metatarsal head with sesamoid impairment. HR clinically presents with stiffness of the first MTP and of the sesamoid complex which causes joint pain and movement restriction in walking and in articular function [4]. There are many options in the treatment of HR according to the age of patients, stage of the disease, activity level and severity of the lesions. For the staging of HR, the Regnauld (1986) classification [5] with the modifications proposed by Collins and Shurnas [6] is largely used. According to the results of the literature, cheilectomy with resection of $25 \%-33 \%$ of the dorsal metatarsal head and proximal phalange osteophyte is advised for the early stage and for grade I and II of HR; larger resection of more than one third of the articular surface may cause instability and subluxation [7-10]. In grade III and IV, the best results have been obtained with arthroplasties (included hemiarthroplasty) and arthrodesis treatment $[9,11,12]$. Although implants, hemiarthroplasty and arthroplasty had demonstrated good results with good joint motion, complications linked to the postoperative first ray instability, shortness, and metatarsal pain have limited the use of this treatment.

The aim of the present study is to compare the pros and cons of two different surgical methods widely reported in literature: arthrodesis and hemiarthroplasty [13-18].

\section{Materials and Methods}

The patients were considered affected by hallux rigidus according to the "International Classification of Diseases, 10 revision" [19] procedure codes (code M20.2). All patients with a hallux valgus $>15^{\circ}$, with gout or with sesamoid-MTP arthritis, and inflammatory arthropathy were excluded. The study was approved by local ethical committee and is in accordance with the Declaration of Helsinki.

The source of the patients was the outpatient department of the Orthopedics Clinic, University of Catania (Catania, Italy). The data were abstracted by two of us and the outcome measurements and statistical analysis were undertaken by one of us.

For the staging of HR we used the Regnauld (1986) classification [5] with the modifications proposed by Collins and Shurnas [6].

We use the following surgical options: arthrodesis, hemiarthroplasty. The arthrodesis was performed through a longitudinal supero-medial incision centered on the first MTP with a longitudinal incision of the capsule with the surgical fusion of the joint using either clevis or screws. On a frontal plane we block the joint in a neutral position; in the transversal plane we block the joint between $15^{\circ}$ and $20^{\circ}$ in valgus; and on a sagittal plane we block the join in dorsiflexion between $20^{\circ}$ and $30^{\circ}$ [11]. The hemiarthroplasty was performed using a metatarsal implant with the aim of preserving the Range Of Motion (ROM), avoiding the arthrodesis. We used Hemicap implant with the technique to resurface the metatarsal head as described by Hasselmann and Shields [9]. At follow-up the patients were evaluated by a clinical investigation and radiographic exam at 1,3 and 6 months. Final evaluation was performed at a median of 48 months (Interquartile Range (IQR) 29,33-58). The outcome was assessed using the Hallux Metatarsophalangeal-Interphalangeal (HMI) scale by from the American Orthopedic Foot and Ankle Society (AOFAS) [13,20]. No modifications of this score were used despite the fact that an arthrodesis of the first MTP joint results in a maximum score of only 90, as 10 points are assigned for MTP joint motion. The Numeric Rating Scale (NRS) scale was used to report the level of pain. The different surgical procedures were made by two different surgeons who, however, did not take part in the calculation of the score. No comparison group was considered and no explanatory analysis was performed. The AOFAS score was recorded before surgery, one month after surgery and then with a mean follow-up of 36 months (24-48 months) by two different investigators.

Continuous variables were reported as median and IQR, whereas discrete and categorical variables were reported as count and percent value. We used Wilcoxon test for related samples to compare AOFAS-HMI scores preoperatively, postoperatively and at follow-up for all patients. For each group and between groups, Models of Pearson's correlations were created to test the relationship between 
the AOFAS-HMI score with the grade of HR. For statistical analysis we used Ministat Software 2.1 (ministat.software.informer.com).

\section{Postoperative Rehabilitation [10]}

In hemiarthroplasty, weight-bearing is allowed one day after surgery with Baruk shoes. Rigid shoes are allowed 15 days after surgery. After hemiarthroplasty we propose this protocol: rehabilitation starts when the stitches are removed, giving priority to the flexibility in every phase of rehabilitation. Phase 1 (1-15 days): rest, Non Steroideal Anti-Inflammatory Drugs (NSAIDs) and ice. Gentle mobilization (day 7) of the first MTP joint and stretching exercises for the plantar fascia. Phase 2 (2-6 weeks): ice, active and passive mobilization of first MTP joint, stretching of plantar fascia and gastrocnemius muscle. We allow progressive weight-bearing with rigid shoes. Gradually the patient starts with proprioceptive exercises Biomechanical Ankle Platform System (BAPS) board). Phase 3: while continuing rehabilitation the patient progressively returns to daily life activities, checking for pain or rigidity relapse. After arthrodesis, the patient walks with Baruk shoes for 30 days and then we allow progressive weight-bearing with rigid shoes, and even in the patients stretching the plantar fascia and doing proprioceptive exercises are allowed after 30 days.

\section{Results}

This is a retrospective case series including 12 patients $(n=14 \mathrm{HR})$ undergoing surgery from July 2004 to October 2009 ( 5 years, 4 months). There were 10 females and 2 males. The median age was 58 years old (IQR 52.75-65.0).

At the time of surgery, patients had different grades of HR: 3 (21.4\%) were grade II; 11 (78.6\%) were grade III. $8(57.2 \%)$ with HR, 3 with grade II and 5 with grade III, underwent hemiarthroplasty. $6(42 . \%)$ with HR with grade III underwent arthrodesis of the first MTP joint (Table 1).

Table 1. Patients and methods (13 patients and 14 feet).

\begin{tabular}{cc}
\hline Parameters & Value \\
\hline Patients & 12 \\
Feet & 14 \\
Mean age (months) & 57.7 \\
Males & 2 \\
Females & 10 \\
Arthrodesis (feet) & 6 \\
Arthroplasty (feet) & 8 \\
Grade II (feet) & 3 \\
Grade III (feet) & 11 \\
\hline
\end{tabular}

After a median follow-up of 48 months (IQR 29.33-58), in the arthrodesis group we observed an improvement of the median AOFAS score of 35.5 points (IQR 34.75-36.0, $p=0.036$ ). The clinical outcome, however, was considered satisfactory by all patients, with a good recovery and no pain at three months, despite the loss of strength and function of the first MTP joint. No significant modification at follow-up was observed.

In the hemiarthroplasty group, at the median follow-up of 36 months, the median of differences was 33 points (IQR 30.5-33, $p=0.022$ ). Relative to the hemiarthroplasty group, two patients still complained of mild pain after 3 months (EVA 3/10) whereas no patient complained of pain after 3 months in the arthrodesis group.

At middle-term follow-up, the hemiarthroplasty group showed the lowest median difference score (30.5; IQR 28-32.5) in comparison with the arthrodesis group (35; IQR 33.0-35.25). However, this difference was not significant (Table 2). 
Table 2. Evaluation of the results of our patients according to the type of treatment and grade of involvement (14 feet).

\begin{tabular}{cccccccc}
\hline Procedure & N. of Feet & Grade II & Grade III & $\begin{array}{c}\text { AOFAS Preoperative } \\
\text { (Median) }\end{array}$ & $\begin{array}{c}\text { AOFAS Postoperative } \\
\text { (Median) }\end{array}$ & $\begin{array}{c}\text { AOFAS Control } \\
\text { (Median) }\end{array}$ & $\begin{array}{c}\text { Pre-Postoperative Difference } \\
\text { (Median of Differences) }\end{array}$ \\
\hline $\begin{array}{c}\boldsymbol{p} \text { Value } \\
\text { Hemiarthroplasty }\end{array}$ & 8 & 3 & 5 & 52 & 85 & 81.5 & 33.0 \\
Arthrodesis & 6 & 0 & 6 & 45 & 81 & 0.022 \\
\hline
\end{tabular}

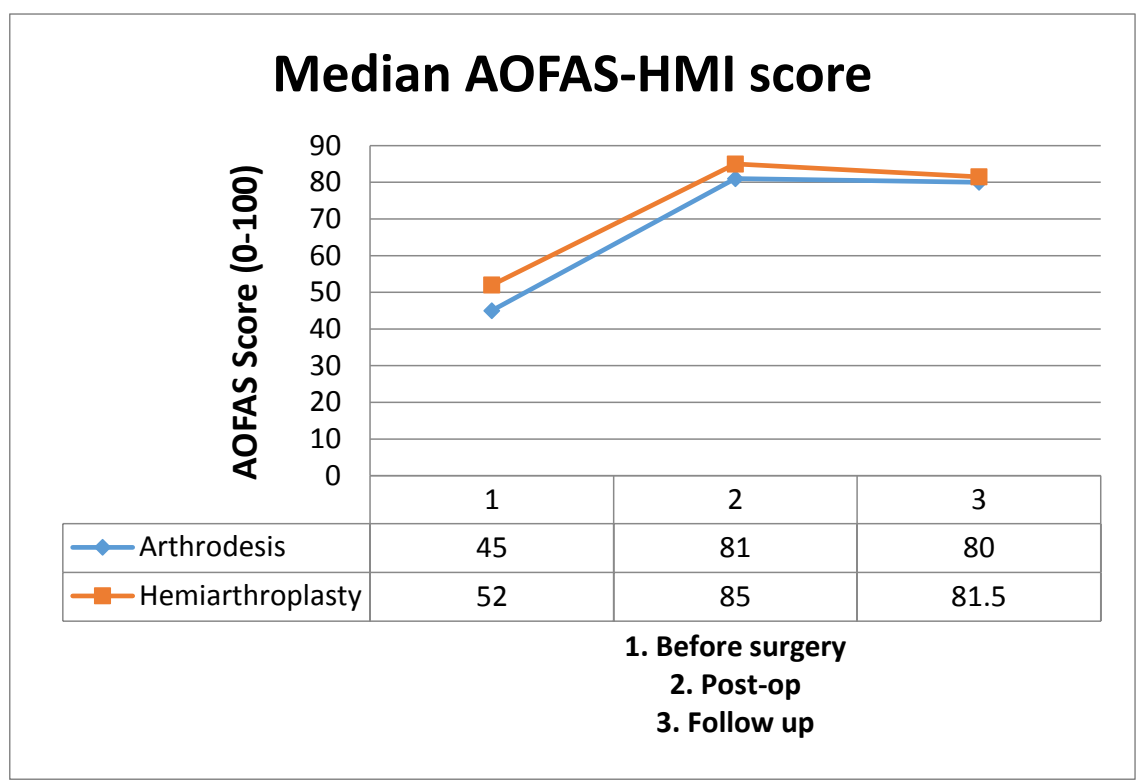

Figure 1. Median of AOFAS score for the two different procedures (14 feet). 
No general complications such as infections or neurovascular injuries occurred. In one case, the loosening of the implant (hemiarthroplasty) was observed after one year, and in this case an arthrodesis was performed.

In our series, the grade of HR (radiological classification) seems to be related with the preoperative AOFAS-HMI score $(r=-0.77)$.

\section{Discussion}

In our series, both techniques showed good results at short-term follow-up. At a mid-term follow-up the prosthetic implants had worse results in terms of pain, joint motion and complications.

The small number of cases may have limited our ability to recognize a significant difference between groups, in particular in the arthrodesis series. Relative to the hemiarthroplasty group, two patients still complained of mild pain after 3 months (EVA 3/10) whereas no patient complained of pain after 3 months in the arthrodesis group. This observation was taken into account during the AOFAS-HMI score evaluation although we cannot consider it a failure (Figure 1). The lack of post hoc power analysis, in consideration of the number of cases, is the main limitation of the study.

Hasselmann and Shields [9] showed good results with the Hemicap metatarsal implant at 20 months in a case series of 100 feet. Erdil et al. [17] reported good results with the Hemicap implant in 14 feet at a short-term follow-up. However, there are few case series in literature with these implants. An article by Hopson et al. [21] describes the failure of one of these implants due to mobilization. Looking at the phalangeal implants, Giza et al. [18] published the results of a series of 22 feet treated with phalangeal hemiarthroplasty. They showed good results with two implant revisions, but overall there seems to be no significant difference with metatarsal implants. Sorbie and Saunders [22], in a prospective study on 23 patients, used a cemented phalangeal hemiarthroplasty and reported an improvement of the motion from 57 points (range 39-80) on the preoperative AOFAS to 88 points (range 75-100) at a follow-up of 34-72 months. No complications were reported by the authors, with the exception of a small hematoma; only one patient, 3 years after the treatment, required a new surgical approach to repair the pre-existing hallux valgus.

Arthrodesis is indicated in severe HR (grade III with poor motility and grade IV) in all patients who, because of their activity, need the stability of the joint: there is an aesthetic contraindication in women who do not want to renounce high heels. Different techniques have been described for the joint fusion, with one screw, two screws, $\mathrm{K}$ wire or clavis. All authors insist on the stability of the synthesis to avoid non-union and pain $[11,12,14-16,23]$. Arthrodesis is the treatment of choice when there is less than $50 \%$ of the metatarsal joint surface in good condition and as a rescue treatment after other techniques $[6,8,13-15]$. Complications of this treatment consist of poor alignment, non-union, and degenerative arthropathy of the hallux interphalangeal joint. Beeson [8] in his review states the percentage of success of an arthrodesis at $90 \%$, with a residual pain present in $22 \%-30 \%$ of cases.

Raikin et al. [24], in a retrospective series comparing the course of patients with severe first MTP arthritis, treated patients with arthrodesis vs. hemiarthroplasty with the Bio Pro implant: better results were obtained in the group treated with the arthrodesis, with results of $87 \%$ improving $v s .60 \%$, respectively. In the group where treatment with arthrodesis was performed, no surgical revision was necessary and fusion was obtained by 12 weeks after surgery. However, patients in this group suffered minor complications consisting of irritation caused by the screw head, plantar callosity and instability of the second MTP joint.

In conclusion, HR is an underestimated pathology that can affect both younger and older patients. HR is often under-valued in the initial phase when the clinical signs are poor. In the advanced (grade III and IV) phase, it is a debilitating pathology that has a great effect on walking ability. At this phase every conservative approach is ineffective and surgery is the only option. Several techniques are described to treat HR. In our study we considered only two options. Nowadays, arthrodesis is considered, according to most authors, the treatment of choice in grade III and IV HR and our results confirm this statement. Good results in the short term still have to be confirmed, with more 
consistent case series at long-term follow-up. Concerns still exist about treatment with arthroplasty, and more investigations are needed, especially to compare the different implants often characterized by different philosophies (total replacement, metatarsal or phalangeal). There is a small amount of literature about rehabilitation after HR surgery [25]. In our opinion, the main goals to achieve are: the management of pain, and working on joint mobility in order to restore the correct dynamic of the step. It is fundamental, for preventing relapses, to restore the ROM of the first MTP joint in dorsal flexion.

Author Contributions: Manuscript has been read and commented by all coauthors. The data were abstracted by Gianluca Testa and Luca Cannavò and the outcomemeasurements and statistical analysis were undertaken by Marco De Gori The operation and follow up control were performed by Luciano Costarella, Vito Pavone and Giuseppe Sessa.

Conflicts of Interest: The authors declare no conflict of interest.

Financial Disclosure: The authors received no financial support for the research, authorship and/or publication of this article.

\section{References}

1. Davies-Colley, N. Contraction of the metatarsophalangeal joint of the great toe (hallux flexus). Br. Med. J. 1887, 1, 728 .

2. Rubio-Lorenzo, M.; Prieto-Montaña, J.R. Epidemiological factors of hallux rigidus. J. Bone Jt. Surg. 2009, 91B, 324 .

3. Scarfi, G; Veneziani, C. Alluce rigido: semeiotica clinica e strumentale. In L'alluce Rigido, monografia della Società Italiana di Medicina e Chirurgia del piede; De Palma, L., Giannini, S., Eds.; Bologna: Rome, Italy, 2001; Volume 1, pp. 21-26.

4. Shereff, M.J.; Baumhauer, J.F. Hallux rigidus and osteoarthrosis of the first metatarsophalangeal joint. J. Bone Jt. Surg. 1998, 80, 898-909.

5. Regnauld, B. Disorders of the great toe. In The Foot: Pathology, Aetiology, Seminology, Clinical Investigation and Treatment; Springer-Verlag: Berlin, Germany, 1986; pp. 345-359.

6. Collins, M.J.; Shurnas, P.S. Hallux rigidus: Grading and long term results of operative treatment. J. Bone Jt. Surg. 2003, 85A, 2072-2088.

7. Olms, K.; Dietze, A. Replacement arthroplasty for hallux rigidus. Int. Orthop. 1999, 23, 240-243. [CrossRef] [PubMed]

8. Beeson, P. The surgical treatment of hallux limitus/rigidus: A critical review of the literature. Foot. 2004, 14, 6-22. [CrossRef]

9. Hasselman, C.T.; Shields, N. Resurfacing of the first metatarsal head in the treatment of hallux rigidus. Tech. Foot Ankle Surg. 2008, 7, 31-40. [CrossRef]

10. Martinelli, N.; Denaro, V.; Gosheger, G.; Pejman, Z.; Buchhorn, T. Recreational sport activity after total replacement of the first metatarsophalangeal joint: a prospective study. Int. Orthop. 2010, 34, 973-979.

11. Andreasi, A.; Ceschi, M. L'artrodesi della I metatarsofalangea nell'alluce rigido. In L'alluce Rigido, monografia della Società Italiana di Medicina e Chirurgia del piede; De Palma, L., Giannini, S., Eds.; Bologna: Rome, Italy, 2001; pp. 139-152.

12. Wassink, S.; van den Oeven, M. Arthrodesis of the first metatarsophalangeal joint using a single screw: Retrospective analysis of 109 feet. J. Foot Ankle Surg. 2009, 48, 653-661. [CrossRef] [PubMed]

13. Kitaoka, H.B.; Alexander, I.J.; Adelaar, R.S.; Nunley, J.A.; Myerson, M.S.; Sanders, M. Clinical rating systems for the ankle-hindfoot, midfoot, hallux, and lesser toes. Foot Ankle Int. 1994, 15, 349-353. [CrossRef] [PubMed]

14. Mann, R.A.; Clanton, T.O. Hallux rigidus: treatment by cheilectomy. J. Bone Jt. Surg. 1988, 70A, 400-406. [CrossRef]

15. Verrina, F. La cheilectomia nel trattamento chirurgico dell'alluce rigido. In L'alluce Rigido, monografia della Società Italiana di Medicina e Chirurgia del piede; De Palma, L., Giannini, S., Eds.; Bologna: Rome, Italy, 2001; Volume 1, pp. 59-64. 
16. Brosky, T.A.; Menke, C.R.; Xenos, D. Reconstruction of the first metatarsophalangeal joint following post-cheilectomy avascular necrosis of the first metatarsal head: A case report. J. Foot Ankle Surg. 2009, 48, 61-69. [CrossRef] [PubMed]

17. Erdil, M.; Bilsel, K.; Imren, Y.; Mutlu, S.; Güler, O.; Gürkan, V.; Elmadağ, N.M.; Tuncay, I. Metatarsal head resurfacing hemiarthroplasty in the treatment of advanced stage hallux rigidus: Outcomes in the short-term. Acta Orthop. Traumatol. Turc. 2012, 46, 281-285. [CrossRef] [PubMed]

18. Giza, E.; Sullivan, M.; Ocel, D.; Lundeen, G.; Mitchell, M.; Frizzell, L. First metatarsophalangeal hemiarthroplasy for hallux rigidus. Int. Orthop. 2010, 34, 1193-1198. [CrossRef] [PubMed]

19. World Health Organization: International Classification of Diseases (ICD). Available online: http:/ /www.who.int/classifications/icd/en/ (accessed on 2 February 2014).

20. Ibrahim, T.; Beiri, A.; Azzabi, M.; Best, A.J.; Taylor, G.J.; Menon, D.K. Reliability and validity of the subjective component of the American Orthopaedic Foot and Ankle Society clinical rating scales. J. Foot Ankle Surg. 2007, 46, 65-74. [CrossRef] [PubMed]

21. Hopson, M.; Stone, P.; Paden, M. First metatarsal head osteoarticular transfer system for salvage of a failedhemicap-implant: A case report. J. Foot Ankle Surg. 2009, 48, 483-487. [CrossRef] [PubMed]

22. Sorbie, C.; Saunders, G.A. Hemiarthroplasty in the treatment of hallux rigidus. Foot Ankle Int. 2008, 29, 273-281. [CrossRef] [PubMed]

23. Mah, C.D.; Banks, A.S. Immediate weight bearing following first metatarsophalangeal joint fusion with Kirschner wire fixation. J. Foot Ankle Surg. 2009, 48, 3-8. [CrossRef] [PubMed]

24. Raikin, S.M.; Ahmad, J.; Pour, A.E.; Abidi, N. Comparison of arthrodesis and metallic hemiarthroplasty of the hallux metatarsophalangeal joint. J. Bone Jt. Surg. 2007, 89A, 1979-1985. [CrossRef] [PubMed]

25. Casillas, M.M.; Jacobs, M. “Alluce Rigido". Sta in: La riabilitazione in ortopedia -II edizione. Brotzman, S.B., Wilk, K.E., Boccardi, S., Eds.; Excerpta Medica: Milano, Italy, 2004; pp. 422-429.

(C) 2016 by the authors; licensee MDPI, Basel, Switzerland. This article is an open access article distributed under the terms and conditions of the Creative Commons by Attribution (CC-BY) license (http:/ / creativecommons.org/licenses/by/4.0/). 